Research Article

\title{
Climate Regionalization of Asphalt Pavement Based on the K-Means Clustering Algorithm
}

\author{
Yanhai Yang $\mathbb{D},{ }^{1}$ Baitong Qian $\mathbb{D}^{1},{ }^{1}$ Qicheng Xu $\mathbb{D}{ }^{2}$ and Ye Yang $\mathbb{D}{ }^{1,3}$ \\ ${ }^{1}$ School of Transportation Engineering, Shenyang Jianzhu University, Shenyang 110168, China \\ ${ }^{2}$ College of Science, Shenyang Jianzhu University, Shenyang 110168, China \\ ${ }^{3}$ College of Transportation Engineering, Dalian Maritime University, Dalian 116026, China
}

Correspondence should be addressed to Ye Yang; yangye@sjzu.edu.cn

Received 20 November 2019; Revised 23 May 2020; Accepted 26 May 2020; Published 22 June 2020

Academic Editor: Valeria Vignali

Copyright ( $\odot 2020$ Yanhai Yang et al. This is an open access article distributed under the Creative Commons Attribution License, which permits unrestricted use, distribution, and reproduction in any medium, provided the original work is properly cited.

\begin{abstract}
The climate regionalization of asphalt pavement plays an active role in ensuring the good performance and service life of asphalt pavement. In order to better adapt to the climate characteristics of a region, this study developed a multi-index method of climate regionalization of asphalt pavement. First, meteorological data from the research region were statistically analyzed and the major climate variables were identified. Then, a principal component analysis (PCA) was used to eliminate any correlation between the major climate variables. Three principal components were extracted by the PCA as cluster factors, namely, the temperature factor, precipitation factor, and radiation factor. The research region was divided into the following four asphalt pavement climate zones via the K-means clustering algorithm. Those zones are affected by the climate comprehensively: an inland zone with high temperatures, little rainfall, and radiation, a coastal zone with high temperatures, and a rainy mountainous zone. The results of the climate regionalization were compared with the results of on-site investigations. The pavement degradation in each climatic zone was related to the climate characteristics of the region. Probabilistic neural network (PNN) and support vector machine (SVM) climate regionalization predictive models were established with MATLAB. The clustering factors were used as the input data to identify the climate zones, and the identification accuracy rate was determined to be over $90 \%$. The climate regionalization of pavement can provide reference and guidance for the selection of reasonable technical measures, parameters, and building materials in highway projects with similar climatic conditions.
\end{abstract}

\section{Introduction}

The performance of asphalt pavement is affected by many environmental factors such as temperature, precipitation, and solar radiation, during its service period. In addition, the bearing capacity and service performance of asphalt pavements are attenuated continuously [1]. The asphalt pavement structure should be coordinated with the natural environment and adapted to the climate characteristics of the region. In this way, typical service performance and service life can be guaranteed [2]. Therefore, many researchers try to analyze and study the climate conditions expected during the road construction process and service period. And then, local plans of the climate regionalization of asphalt pavements are proposed. These plans are used to guide the selection of asphalt materials, mixture design, and reasonable construction methods for the pavements.

In recent years, many countries have focused on the temporal and spatial variability of climate elements and established the standards of the regionalization of asphalt pavement. The Performance Grade (PG) method and standard for matrix asphalt were proposed by the Strategic Highway Research Program in America. Asphalt is divided into four grades based on the highest average pavement temperature for seven continuous days and the extreme minimum air temperature in a year [3]. Subsequently, other countries began to introduce and carried out native analysis of applicability. Based on the high temperature, low temperature, and precipitation indexes, the method of the climate regionalization for asphalt pavement performance was proposed in China [4]. The climatic regionalization of 
asphalt under temperature conditions in Poland was established based on the standard of PG $[5,6]$. Similarly, other countries such as Jordan [7], Italy [8], Thailand [9], and Iran [10] have developed the plans of the climate regionalization according to the extreme temperature range that the asphalt will be subjected to. In these methods, a Geographic Information System (GIS) is used to draw intuitive maps of the climate regionalization [11]. Spatial interpolation methods are used to process complex meteorological data [12]. Most standard methods used in previous studies are applied according to temperature and precipitation directly. However, the climate regionalization established only based on few climate factors is obviously not reasonable enough. More climate factors should be considered in the regionalization plans. But there are often correlations between the complex climate factors considered. This will not make the plans of the climate regionalization also adequately reveal the different effects of climatic conditions on asphalt pavement. And the results of the climate regionalization are also relatively inaccurate and cannot completely meet practical needs. Therefore, other accurate methods of the climate regionalization that comprehensively consider multiple climatic factors need to be developed. Principle clustering analyses (PCA) and clustering algorithms have been widely used to define different climate zones in processing meteorology and geography data [13]. The main impact factors can be selected from the complex climate impact factors determined by PCA and defined as principal components [14]. And the homogeneous regions can be identified using clustering techniques $[15,16]$. It is necessary to integrate the two methods described here into the climate regionalization of asphalt pavement. This comprehensive method can eliminate the correlation between evaluation indexes to obtain more accurate clustering results.

To this end, this study proposes a multi-index method for the climate regionalization of asphalt pavements based on the K-means clustering algorithm. This method takes into account various climatic factors and eliminates the correlation between those factors. The climate data of Liaoning Province from 2001 to 2014 are statistically analyzed. The effects of high temperatures, low temperatures, precipitation, and solar radiation are considered comprehensively. To verify the accuracy of the regionalization effect, we conducted a road degradation survey in the research region. The results of the climate regionalization were found to be consistent with the actual road conditions as established by a comparative analysis. In addition, a probabilistic neural network (PNN) prediction model and the support vector machine (SVM) prediction model were constructed and found to accurately predict the partition results. This method can be used to guide the selection of pavement materials and design of asphalt mixtures of construction.

\section{Research Methodology}

2.1. Principal Component Analysis. A PCA is a dimensionality reduction method based on a linear transformation. This method can convert a high-dimensional data set into low-dimensional space by some linear transformation. And then the problem to be solved is converted into one of determined covariance matrix eigenvalues and eigenvectors of the sample data. The goal of a PCA is to reflect the variation in the sample data with a data set characterized by lower dimensionality. It also completes the transformation of a set of potentially correlated variables into a set of linearly uncorrelated variables, thereby simplifying the calculations [17].

Each sample, $X$, has $\mathrm{n}$-dimensional characteristics, $X=$ $\left(x_{1}, x_{2}, \ldots, x_{n}\right)^{T}$ in the sample space. At the same time, each feature meets the conditions $x_{i} \in R^{n}$ and $(1 / n) \sum_{i=1}^{n} x_{i}=0$. The covariance matrix of the sample is shown in

$$
C=\left[\begin{array}{cccc}
c_{11} & c_{12} & \ldots & c_{1 n} \\
c_{21} & c_{22} & \ldots & c_{2 n} \\
\vdots & \vdots & \ddots & \vdots \\
c_{n 1} & c_{n 2} & \ldots & c_{n n}
\end{array}\right],
$$

where $c_{i j}=\operatorname{Cov}\left(x_{i}, x_{j}\right), i, j=1,2, \ldots, n$.

The eigenvalues of the covariance matrix, $\lambda_{1} \geq \lambda_{2} \geq \cdots \lambda_{n} \geq 0$, and the corresponding eigenvectors, $u_{1}, u_{2}, \ldots, u_{n}$, are obtained according to the characteristic equation $\mathrm{CU}=\lambda u$. The $i$ th principal component is $F_{i}$ by projection. The calculation is shown in

$$
F_{i}=u_{i 1} x_{1}+u_{i 2} x_{2}+\cdots+u_{i n} x_{n}
$$

$\lambda_{i} / \sum_{i=1}^{N} \lambda_{i}$ is defined as the contribution rate of the principal component $F_{i}$. $\left(\sum_{i=1}^{k} \lambda_{i} / \sum_{i=1}^{N} \lambda_{i}\right)$ is the cumulative contribution rate of $F_{i}$. The greater the cumulative contribution rate, the smaller the body of information that is lost. When the cumulative contribution rate is more than $85 \%$, the principal components selected contain the most information of the original variables $[18,19]$. Therefore, we take the principal component with a cumulative contribution rate greater than $85 \%$ as the comprehensive index to best reflect the information of the sample data.

2.2. K-Means Clustering Algorithm. The K-means clustering algorithm is an unsupervised learning method. In this method, the sum of the distances from the data points to the initial clustering center is taken as a clustering criterion function. The adjustment rule of the iterative operation is obtained by solving for the extreme values of the function. Similar data points are clustered into corresponding $\mathrm{K}$ clusters through repeated iterative operations. The optimal classification of the sample data is ultimately obtained [20].

Each sample meets the condition $x^{(i)} \in R^{n}$ in the m-dimensional sample space $X=\left\{x^{(1)}, x^{(2)}, \ldots, x^{(m)}\right\}$. K-cluster centroid points $\mu_{1}, \mu_{2}, \ldots, \mu_{K} \in R^{n}$ are randomly selected as the initial cluster centers. The squared errors of the algorithm and the criterion function are defined in

$$
J_{c}=\sum_{i=1}^{N} \sum_{k=1}^{K} \Gamma_{i k}\left|x_{i}-\mu_{k}\right|^{2},
$$

where $\Gamma_{i k}$ is 1 when data point $i$ is classified into the Kth cluster. Otherwise, $\Gamma_{i k}$ is 0 . 
As $J_{c}$ becomes smaller, the clustering process gradually reaches a steady state. The iterative operation ends when $J_{c}$ reaches a minimum value. In order to ensure that the true minimum value of $J_{c}$ is reached, an iterative operation is adopted and $\mu_{k}$ is initially fixed to select the optimal $\Gamma_{i k}$. As long as the data point is classified to the nearest cluster center, $J_{c}$ can be guaranteed to be the minimum. Then, $\Gamma_{i k}$ is fixed to solve for the optimal $\mu_{k}$. It is a straightforward operation to obtain the minimum value of $J_{c}$ when $\mu_{k}$ is the average of the data points in all clusters by differentiating $J_{c}$ with respect to $\mu_{k}$ and setting the derivative equal to zero. The iterative operation formula is shown in

$$
\mu_{k}=\frac{\sum_{N} \Gamma_{N k} x_{N}}{\sum_{N} \Gamma_{N k}} .
$$

2.3. Probabilistic Neural Network. The PNN is a parallel algorithm based on the Bayesian classification rules and probability density function estimation methods. PNNs can realize the functionality of a nonlinear learning algorithm by using a linear learning algorithm [21] and exhibits the high precision of nonlinear algorithms. The PNN algorithm includes an input layer, a pattern layer, a summation layer, and an output layer [22]. The structure of the PNN used in this study is shown in Figure 1.

The input layer passes the input eigenvector to each node of the pattern layer through a linear function. This results in a scalar product with a weighted sum, as shown in

$$
Z_{i}=x \cdot w_{i},
$$

where $x$ is the input eigenvector and $w_{i}$ is a weighted coefficient corresponding to the eigenvector.

The degree of matching between the input eigenvector and each pattern in training set is calculated in the pattern layer. And then the input eigenvector is sent to a Gaussian distance function to obtain the output result. The radial basis operation $\exp \left[\left(Z_{i}-1\right) / \sigma^{2}\right]$ is used as the activation function in the pattern layer. The input and output relations corresponding to the $j$ th neuron of the $i$ th mode are determined by

$$
\varphi_{i j}(x)=\frac{1}{\sqrt{2 \pi} \sigma^{d}} \exp \left[-\frac{\left(x-x_{i j}\right)^{T}\left(x-x_{i j}\right)}{2 \sigma^{2}}\right],
$$

where, $i=1,2, \ldots, M, M$ is the total number of training samples; $j=1,2, \ldots, N_{i}, N_{i}$ is the number in training samples of category $i$; $d$ is the dimension of the sample space data; $x_{i j}$ is the $j$ th center of the samples of in category $i$; and $\sigma$ is the smoothing factor.

The summation layer is responsible for connecting the neurons belonging to the same category in the pattern layer and finding the weighted average in accordance with

$$
v_{i}=\frac{\sum_{j=1}^{N} \varphi_{i j}}{N_{i}},
$$

where $v_{i}$ is the output of category $i$ and $N_{i}$ is the number of neurons in category $i$.

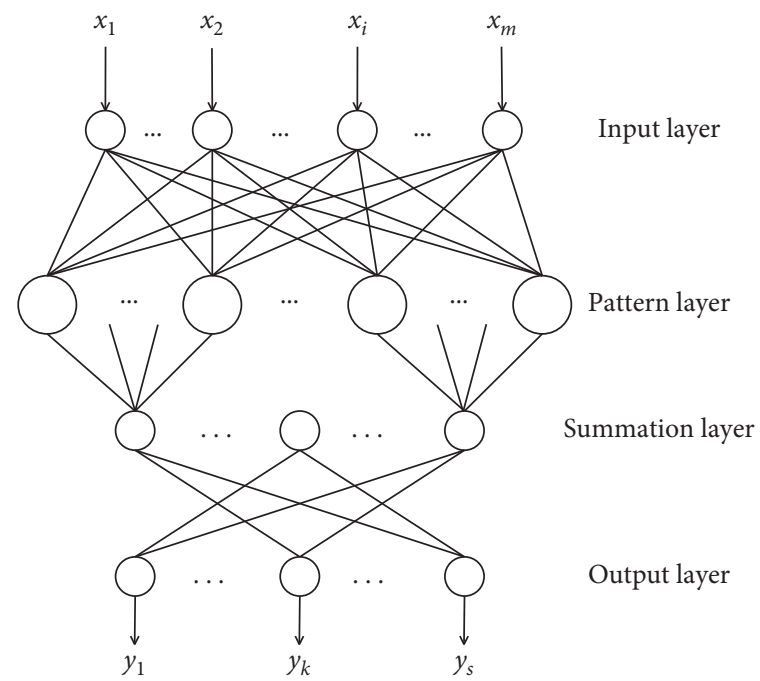

FIgURE 1: The structure of PNN.

The output layer is responsible for producing the category with the highest weighted average in the summation layer, as given by

$$
y=\arg \max \left(v_{i}\right) .
$$

2.4. Support Vector Machine. SVM is a generalized linear classifier used for the binary classification of data with good separation effects. The climate regionalization challenge in this work was to solve a multiclassification problem. Therefore, it was necessary to combine multiple binary classifiers to construct a multiclassifier. The "one-on-one" method has a higher test accuracy when there are fewer categories [23]. Therefore, this study utilized a "one-on-one" method to build a multivariate classification SVM. The calculation process is shown in Figure 2.

The "one-to-one" SVM makes use of a voting methodology. First, a decision boundary is established for any two of $n$ samples, meaning that there are a total of $C_{n}^{2}$ decision boundaries. Each decision boundary produces a classification result and a vote for a category. Then, the number of votes for each type is determined. Finally, the category with the highest number of votes is defined as the classification of the sample. For the decision boundary consisting of the samples in category $i$ (labeled " +1 ") and category $j$ (labeled " -1 "), the optimal decision function is found by using

$$
\begin{array}{ll}
\min & {\left[\frac{1}{2}\left(w^{i j}\right)^{T} w^{i j}+C \sum_{i=1}^{n} \xi_{i}^{i j}\right]} \\
\text { s.t. } & \left\{\begin{array}{l}
y_{i}\left(w^{i j} \cdot x_{i}-b^{i j}\right)+\xi_{i}^{i j}-1 \geq 0 \\
\xi_{i}^{i j} \geq 0, \quad i=1,2, \ldots, n,
\end{array}\right.
\end{array}
$$




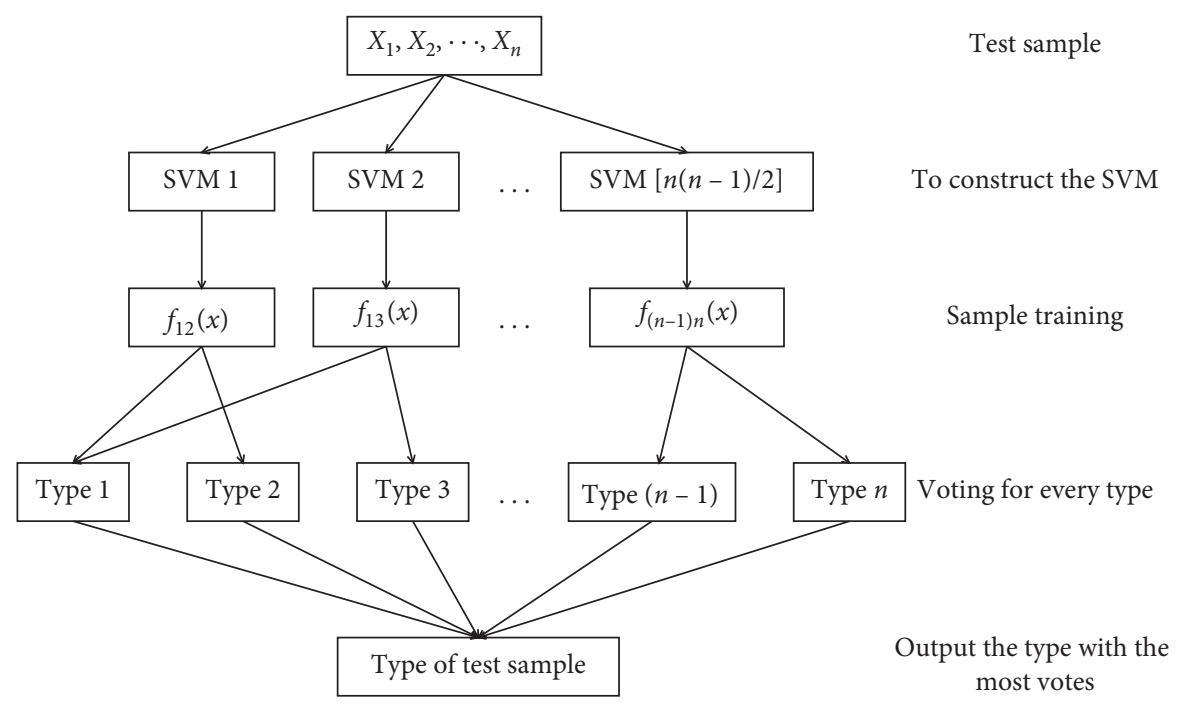

Figure 2: Calculation flow of SVM.

where $C$ is a penalty parameter that controls the degree of penalty applied for the wrong classification sample and $x_{i}$ is the input sample. $w$ is a weight vector. $\xi_{i}^{i j}$ is a slack variable that relaxes the hard boundary constraint.

\section{Climate Regionalization Method}

3.1. Selection of Major Climate Variables. To obtain accurate and reasonable results, we established climate regionalization by considering the effects of major climatic variables on the service performance of asphalt pavements. The major climate variables included high temperature, low temperature, precipitation level, and solar radiation level.

3.1.1. High Temperature. High temperatures have a significant impact on the service life of asphalt pavements and are often the basis of determining the design of the pavement mixture and section. Asphalt becomes a plastomer that deforms under high-temperature conditions, and its shape cannot be completely recovered. Hence, asphalt pavements are prone to permanent deformation under the influence of repeated loading [24], and high temperatures are one of the main causes of the permanent deformation of asphalt pavements. High temperatures also directly affect the smoothness of the pavement and reduce the performance and service life of the road. There is also a direct positive correlation between rut depth, asphalt penetration, and temperature [25]. In addition, high-temperature conditions have a significant effect on the thermal-oxidative aging of asphalt [26]. Therefore, the influence of high temperatures should be considered when implementing climate regionalization.

The maximum high temperature over a span of $n$ years, the annual average maximum temperature, and the annual average temperature were used as the main high-temperature variables. The formulas for each of these parameters are shown in

$$
\begin{gathered}
T_{\text {max,year }}=\frac{1}{n} \sum_{i=1}^{n} T_{\text {max,year }, i} \\
T_{\text {average, max }, \text { year }}=\frac{1}{12} \sum_{i=1}^{12} T_{\text {max }, \text { month }, i}, \\
T_{\text {average,year }}=\frac{1}{12} \sum_{i=1}^{12} T_{\text {average, month }, i},
\end{gathered}
$$

where $T_{\text {max,year }}$ is the maximum high temperature over a span of $n$ years $\left({ }^{\circ} \mathrm{C}\right), T_{\max , y e a r, i}$ is the maximum high temperature in year $i\left({ }^{\circ} \mathrm{C}\right), T_{\text {average, max ,year }}$ is the annual average maximum temperature $\left({ }^{\circ} \mathrm{C}\right), T_{\max , \text { month, } i}$ is the maximum temperature in month $i\left({ }^{\circ} \mathrm{C}\right), T_{\text {average,year }}$ is the annual average temperature $\left({ }^{\circ} \mathrm{C}\right)$, and $T_{\text {average,month, } i}$ is the annual average temperature in month $i\left({ }^{\circ} \mathrm{C}\right)$.

3.1.2. Low Temperature. Asphalt pavements are prone to temperature stresses which often result in the formation of cracks in low-temperature environments [27]. Generally, asphalt mixtures have good low-temperature crack resistance [28]. But cracking tends to become more severe with repeated fatigue due to seasonal alternation and temperature cycling. A large area of the alligator cracking will often appear. These cracks will shorten the service life of roads dramatically. This is one of the main forms of damage to asphalt pavement. Liaoning Province is a large province in China with frequent freeze-thaw cycles. The low-temperature degradation of asphalt pavements is particularly prominent. Therefore, low-temperature factors must also be considered when implementing climate regionalization.

The minimum low temperature over a span of $n$ years and annual average minimum temperature were used as the main low-temperature variables for the calculation. The formulas for those parameters are shown in 


$$
\begin{gathered}
T_{\text {min,year }}=\frac{1}{n} \sum_{i=1}^{n} T_{\text {min }, \text { year }, i} \\
T_{\text {average, min }, y e a r}=\frac{1}{12} \sum_{i=1}^{12} T_{\text {min }, \text { month }, i},
\end{gathered}
$$

where $T_{\text {min,year }}$ is the minimum low temperature over a span of $n$ years $\left({ }^{\circ} \mathrm{C}\right), T_{\text {min,year }, i}$ is the minimum low temperature in year $i\left({ }^{\circ} \mathrm{C}\right), T_{\text {average, min, year }}$ is the annual average low temperature $\left({ }^{\circ} \mathrm{C}\right)$, and $T_{\text {max,month, } i}$ is the minimum low temperature in month $i\left({ }^{\circ} \mathrm{C}\right)$.

3.1.3. Precipitation. The infiltration of water is another cause of early damages to asphalt pavements. Water damage is characterized by pit slot and pavement pumping. Water first penetrates into the asphalt mixture. Then, water will cause the adhesion between asphalt and aggregate to decrease. Water infiltration into the asphalt mixture reduces the adhesion of the asphalt to the aggregate. The damage is more severe especially under vehicle loads and hydrodynamic pressure. The strength and durability of the mixture are reduced and the pavement is often destroyed [29-31]. In addition, snow melting cycles in cold regions will reduce the strength of the bond between the asphalt and skeleton structure. The stability of the pavement structure is reduced and it can be easily destroyed by the impact of continuous external loads $[32,33]$. Therefore, the precipitation factor should be considered when implementing climate regionalization.

The maximum precipitation over a span of $n$ years and the annual average precipitation were used as the main precipitation variables for the calculations. The formulas for those parameters are shown in

$$
\begin{gathered}
P_{\text {max }, \text { year }}=\frac{1}{n} \sum_{i=1}^{n} P_{\max , \text { year }, i}, \\
P_{\text {average,year }}=\frac{1}{12} \sum_{i=1}^{12} P_{\text {average, month }, i},
\end{gathered}
$$

where $P_{\max \text {,year }}$ is the maximum precipitation over a span of $n$ years $(\mathrm{mm}), P_{\text {average,year }}$ is the annual average precipitation $(\mathrm{mm}), P_{\max , y e a r, i}$ is the maximum precipitation in year $i$ $(\mathrm{mm})$, and $P_{\text {average,month, } i}$ is the average precipitation in month $i(\mathrm{~mm})$.

3.1.4. Solar Radiation. Asphalt pavements exposed to the atmosphere absorb a considerable amount of solar radiation. It directly leads to the increase of asphalt pavement temperature and the aging of pavement materials. The maximum temperature of asphalt pavements subjected to solar radiation can reach $60^{\circ} \mathrm{C}-70^{\circ} \mathrm{C}$ [34]. At this time, the antideformation ability of asphalt pavement is greatly reduced, and rut is likely to occur under vehicle loads [24]. Moreover, the intensive solar radiation will also accelerate the thermal oxidation and photooxidation of asphalt materials [35-37]. The long-term ultraviolet radiation causes serious degradation of asphalt performance and attenuates the durability of pavements [38]. Therefore, solar radiation intensity must be considered when implementing climate regionalization.

The maximum radiation over a span of $n$ years and annual average radiation were used as the main radiation variables. The formulas are shown as

$$
\begin{aligned}
R_{\text {max,year }} & =\frac{1}{n} \sum_{i=1}^{n} R_{\text {max,year }, i}, \\
R_{\text {average,year }} & =\frac{1}{12} \sum_{i=1}^{12} R_{\text {average, month }, i},
\end{aligned}
$$

where $R_{\max }$,year is the maximum radiation for a span of $n$ years $\left(10^{8} \mathrm{~J} / \mathrm{m}^{2}\right), R_{\text {average,year }}$ is the annual average radiation $\left(10^{8} \mathrm{~J} / \mathrm{m}^{2}\right), P_{\max , \text { year }, i}$ is the maximum radiation in yeari $\left(10^{8} \mathrm{~J} /\right.$ $\mathrm{m}^{2}$ ), and $P_{\text {average,month, } i}$ is the average radiation in month $i$ $\left(10^{8} \mathrm{~J} / \mathrm{m}^{2}\right)$.

3.2. Sample Clustering. A PCA was implemented via a method based on the eigenvalue decomposition of the covariance matrix. Many correlated climate variables were transformed into a few uncorrelated variables and nine major climate variables from 56 weather stations were used as the input data. First, each major climate variable was subtracted from its respective group average to meet the initial conditions of the PCA. The covariance matrix was calculated according to (1). Then, the eigenvalues and eigenvectors of the covariance matrix were calculated using the SVD function and the eigenvalues were sorted from large to small. The eigenvalues in the Kth cluster and the maximum range were chosen. The appropriate principal components were then selected as the clustering factors using (2) and the condition that the eigenvalue was greater than one. Finally, the clustering factors determined by the PCA were taken as the input data space. The seed point of the initial cluster was determined by the sequential method. These initial clusters seed points were analyzed iteratively according to (3). The optimal classification of the sample data was determined when the iteration caused $J_{c}$ to reach a minimum value.

\section{Case Analysis}

\subsection{Samples and Sources}

4.1.1. Research Region. The Liaoning Province, located between $118^{\circ} 53^{\prime}$ and $125^{\circ} 46^{\prime}$ east longitude and between $38^{\circ} 43^{\prime}$ and $43^{\circ} 26^{\prime}$ north latitude, belongs to the North Temperate Zone. The northern latitude of $42^{\circ}$ experiences a high percentage of annual solar radiation and runs through the central part of Liaoning Province. Liaoning Province is the region with the strongest radiation, the most illumination, the highest temperature, and the shortest frost period in the Northeast. It is located on the east coast of the Eurasian continent. The coastal location results in a temperate continental monsoon climate. Precipitation is concentrated in the summer with relatively constant and abundant rainfall. 
The spatial distribution of the precipitation decreases from southeast to northwest.

4.1.2. Primary Types and Causes of Degradation of the Main Roads. A representative road section in Liaoning Province was selected for an on-site investigation. Core samples were taken to determine the main causes and locations of typical degraded conditions. The primary types and proportions of the pavement degradations in Liaoning Province are shown in Figure 3.

It can be seen from Figure 3 that cracking of the pavement is common in the main roads in Liaoning Province. Alligator cracking, longitudinal cracking, and transverse cracking account for $84.24 \%$ of the total degradation area. Alligator cracking is the most serious, accounting for $32.68 \%$, and is mainly caused by the fatigue of the asphalt layer or inorganic binder layer. Longitudinal cracking accounts for $26.62 \%$ and is mainly caused by insufficient strength of the base layer and vehicle loads shearing. The amount of transverse cracking is roughly equivalent to the amount of longitudinal cracking and accounts for $24.94 \%$ of the degradation area. Transverse cracking is mainly caused by the shrinkage of the asphalt mixture under dry or low-temperature conditions. The cracking of the pavement provides a basis for water damages, which can easily cause deterioration, and accounts for $2.18 \%$ of the degradation area. Of the types of degradation observed at high temperatures, rutting is predominant and accounts for $6.13 \%$ of the degradation area. Rutting is mainly caused by a combination of vehicle loads and environmental factors. The remaining types of degradations are related to construction factors and account for $7.45 \%$ of the degradation area. Climatic conditions are the most important factors and leading causes of these conditions. Overall, vehicle loads and climatic conditions are the main factors that directly affect the performance of asphalt pavements.

\subsection{Results of Regionalization}

4.2.1. Major Climate Variables. According to meteorological data from 2001 to 2014 in Liaoning Province, the major climate variables were determined to be as follows.

The high-temperature variables were calculated with equations (10)-(12), and the statistical results are shown in Figure 4. The annual average temperature in Liaoning Province ranged from about $6^{\circ} \mathrm{C}$ to $13^{\circ} \mathrm{C}$. The maximum temperature was in the range of $33.4^{\circ} \mathrm{C}$ to $41.8^{\circ} \mathrm{C}$, with the maximum temperature of $41.8^{\circ} \mathrm{C}$ in Jinzhou.

The low-temperature variables are calculated with equations (13) and (14), and the statistical results are shown in Figure 5. The minimum temperature in winter is in the range $-41.1^{\circ} \mathrm{C}$ to $-19^{\circ} \mathrm{C}$ and is $-41.1^{\circ} \mathrm{C}$ in Xifeng.

The precipitation variables were calculated with equations (15) and (16), and the statistical results are shown in Figure 6. The average annual precipitation in Liaoning Province reached a maximum value of $1023.4 \mathrm{~mm}$. The upper limit of the annual maximum precipitation over a span of $n$ years was $1765.5 \mathrm{~mm}$.

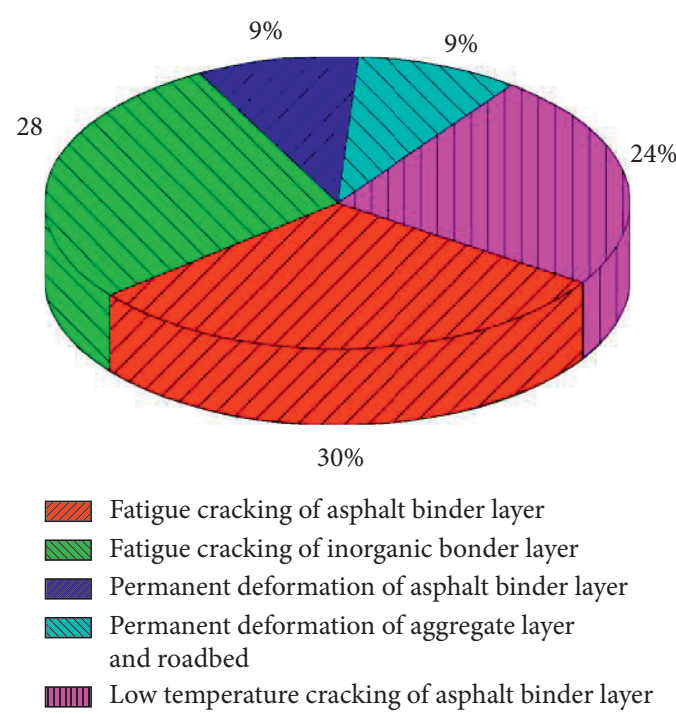

FIgURE 3: Types and proportions of main pavement degradations.

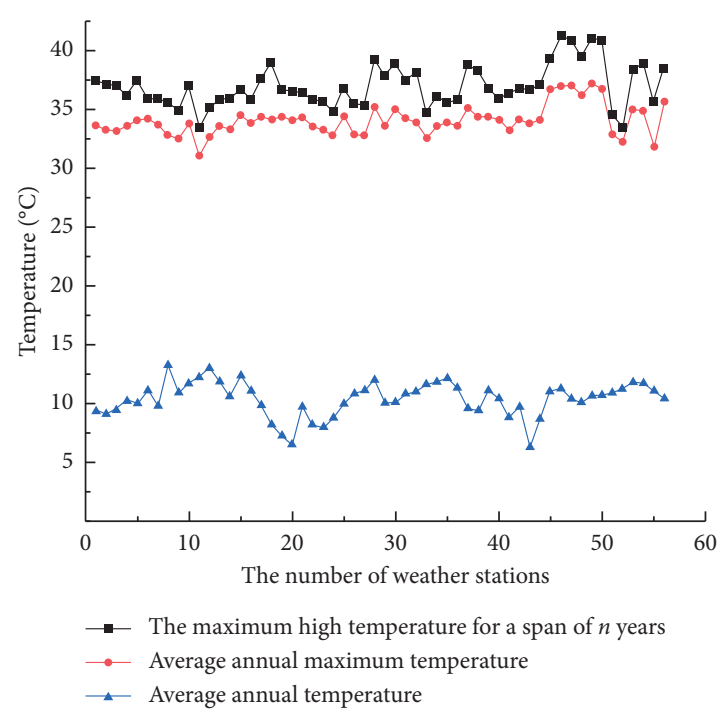

FIgURE 4: Main climate variables of high temperature.

The solar radiation variables were calculated with equations (17) and (18), and the statistical results are shown in Figure 7 . The annual average amount of radiation was within the range of $4.5 \times 10^{8} \mathrm{~J} / \mathrm{m}^{2}$ to $5.5 \times 10^{8} \mathrm{~J} / \mathrm{m}^{2}$. The upper limit of the solar radiation over a span of $n$ years was within the range of $48 \times 10^{8} \mathrm{~J} / \mathrm{m}^{2}$ to $57 \times 10^{8} \mathrm{~J} / \mathrm{m}^{2}$, which is more far than the annual average.

4.2.2. Cluster Factor. The common factor between the nine major climate variables was extracted by means of the main axis method, as shown in Table 1. The second column contains the eigenvalue of each factor. The third column lists the variance contribution rate for each factor. The fourth column is the cumulative variance contribution rate of all factors. The larger the three values in those columns are, the more variable information the factor contains. A cumulative 


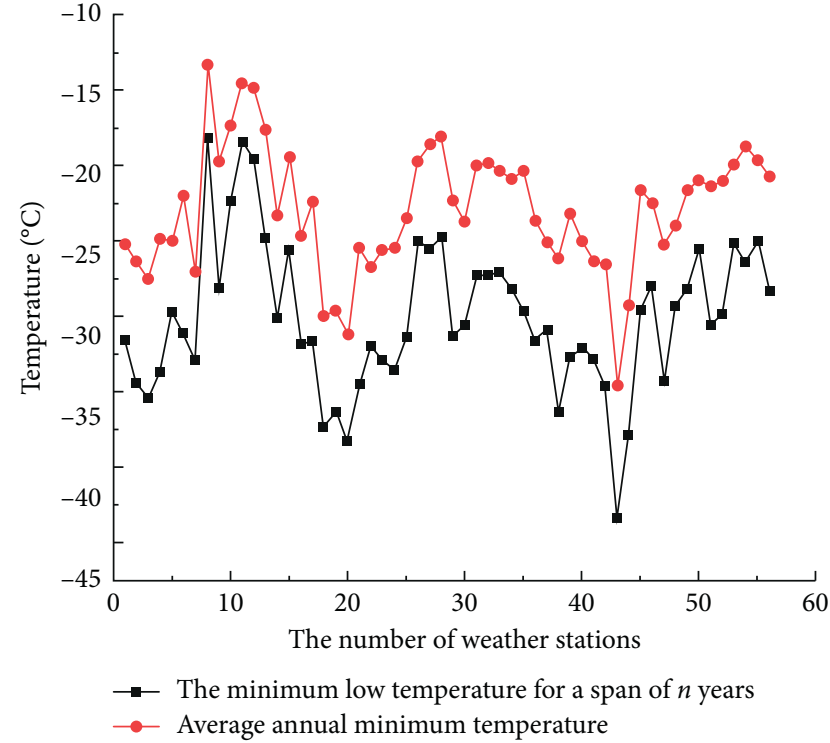

FIgURE 5: Main climate variables of low temperature.

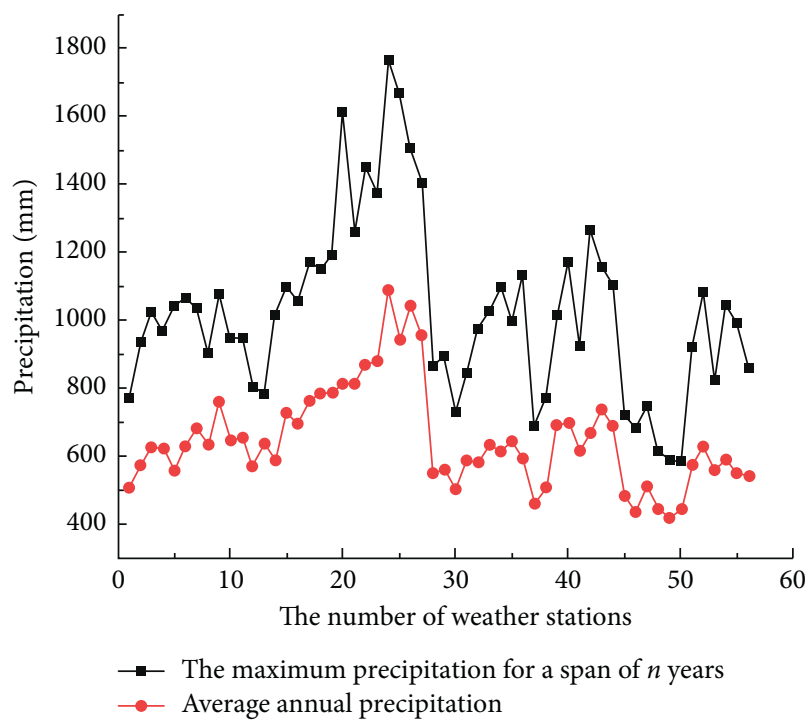

FIgURE 6: Main climate variables of precipitation.

variance contribution rate of $85 \%$ meets the general requirements of this study. Factors with eigenvalues greater than one should be retained and three factors were retained according to this criterion. The cumulative variance contribution rate of these factors reached $88.415 \%$, exceeding the general requirement of $85 \%$.

A steep slope test of the sample factors was performed in MATLAB. The eigenvalues of each factor were ranked from largest to smallest and resulted in a slope according to the theory of PCA. If a factor reduces the eigenvalue of the slope, the eigenvalue of this factor should be defined as a threshold. The factors with eigenvalues at or above the threshold should be retained. In this study, the first three factors were retained, as shown in Figure 8.

The three retained factors were analyzed by the maximum variation method of orthogonal rotation, as shown in

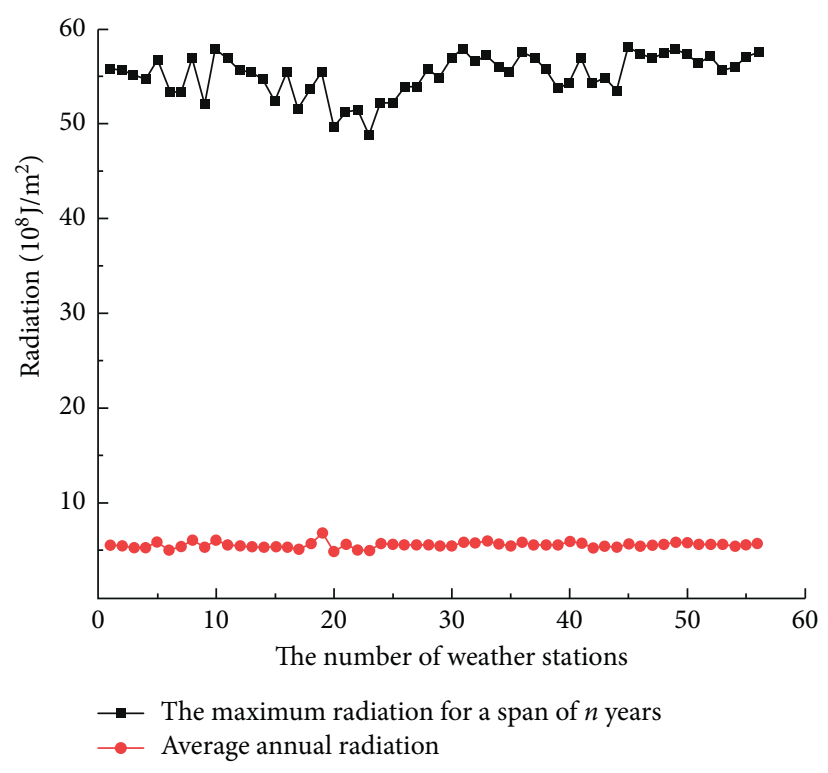

FIgURE 7: Main climate variables of solar radiation.

TABLE 1: Explanation of variance of each principal component.

\begin{tabular}{lccc}
\hline Factors & Eigenvalue & $\begin{array}{c}\text { Variance } \\
\text { contribution rate (\%) }\end{array}$ & $\begin{array}{c}\text { Cumulative variance } \\
\text { contribution rate }(\%)\end{array}$ \\
\hline 1 & 4.175 & 46.389 & 46.389 \\
2 & 2.709 & 30.100 & 76.489 \\
3 & 1.073 & 11.926 & 88.415 \\
4 & 0.547 & 6.075 & 94.490 \\
5 & 0.190 & 2.109 & 96.599 \\
6 & 0.171 & 1.898 & 98.497 \\
7 & 0.062 & 0.690 & 99.186 \\
8 & 0.051 & 0.571 & 99.757 \\
9 & 0.022 & 0.243 & 100.000 \\
\hline
\end{tabular}

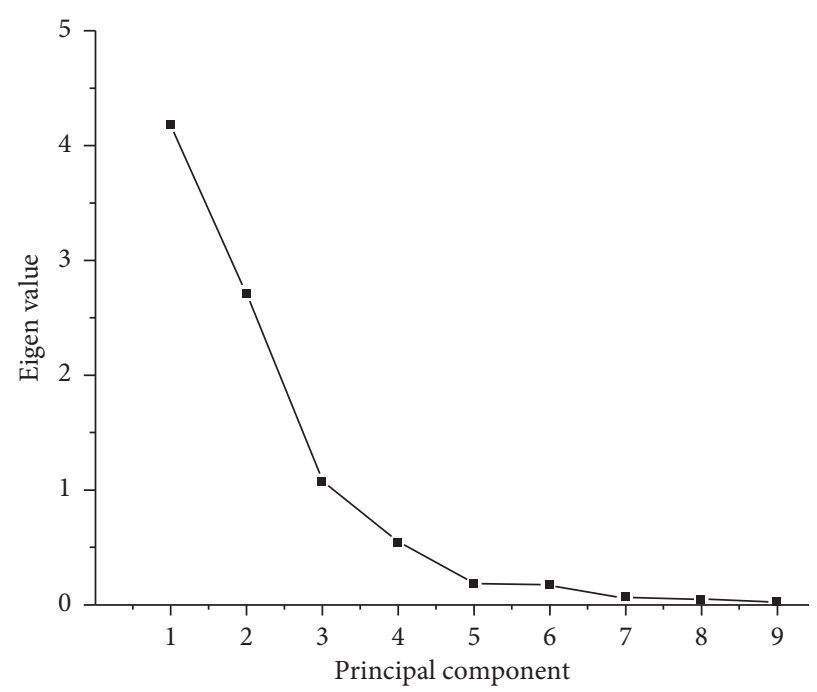

Figure 8: Scree plot.

Table 2. The load value represents the relationship between each factor and the principal component. The greater the load value, the closer the correlation between the factor and 
TABle 2: Principal component load matrix.

\begin{tabular}{lcccc}
\hline \multirow{2}{*}{ Climate factors } & & \multicolumn{4}{c}{ Principal components } \\
& Climate variance & 1 & 2 & 3 \\
\hline \multirow{3}{*}{ Temperature factor } & $T_{\text {max,year }}$ & 0.418 & -0.767 & 0.412 \\
& $T_{\text {min,year }}$ & 0.651 & 0.670 & 0.240 \\
& $T_{\text {average, max ,year }}$ & 0.361 & -0.750 & 0.446 \\
& $T_{\text {average, min,year }}$ & 0.641 & 0.702 & 0.271 \\
& $T_{\text {average,year }}$ & 0.693 & 0.598 & 0.250 \\
Precipitation factor & $P_{\text {max,year }}$ & -0.860 & 0.297 & 0.074 \\
\multirow{3}{*}{ Radiation factor } & $P_{\text {average,year }}$ & -0.810 & 0.394 & 0.092 \\
& $R_{\text {average,year }}$ & 0.864 & -0.078 & -0.357 \\
& $R_{\text {max,year }}$ & 0.642 & -0.106 & -0.608 \\
\hline
\end{tabular}

principal component. The extreme maximum precipitation and the annual average precipitation had higher load values for the first principal component. Each temperature variable had a higher load value for the second principal component, and the annual average radiation and extreme maximum radiation over many years had higher load values for the third principal component. The precipitation factors, temperature factors, and radiation factors were able to explain the original climate variables comprehensively. Therefore, the first, the second, and the third principal components were defined as the precipitation factor, temperature factor, and radiation factor, respectively. The three principal components were then used as clustering factors for the climate regionalization.

All retained factor variables must be uncorrelated, or orthogonal, according to PCA theory. There is no correlation between the factors retained in this study, because the PCA eliminated the correlation between the major climate variables. The covariance matrix of the principal component factors is shown in Table 3.

The scores of the three principal component factors were used as the scores of each clustering factor in the climate regionalization. The clustering factor scores are shown in Figure 9.

4.2.3. Climate Regionalization. The 56 meteorological stations in the research area were divided into four station groups according to the clustering factors obtained with MATLAB. The clustering results are shown in Figure 10.

Finally, ArcGIS was used to delineate the four climate zones resulting from consideration of the asphalt pavement environment, together with regional administrative boundaries. The specific regional types are shown in Figure 11. The results of the climate regionalization are as follows.

Zone I: this zone is significantly affected by high temperatures, low temperatures, and precipitation. This zone includes Fushun, Tieling, Faku, Kangping, and the central and northern parts of Liaoning Province. The extreme minimum temperature reached $-43.4^{\circ} \mathrm{C}$ in the winter. The key in this zone is to improve the lowtemperature crack resistance of asphalt pavements and prevent the occurrence of reflective cracks. An asphalt mixture with a small void ratio, high strength, and good
TABLE 3: The covariance matrix of the principal component factors.

\begin{tabular}{lccc}
\hline Principal component factors & 1 & 2 & 3 \\
\hline 1 & 1.00 & 0.00 & 0.00 \\
2 & 0.00 & 1.00 & 0.00 \\
3 & 0.00 & 0.00 & 1.00 \\
\hline
\end{tabular}

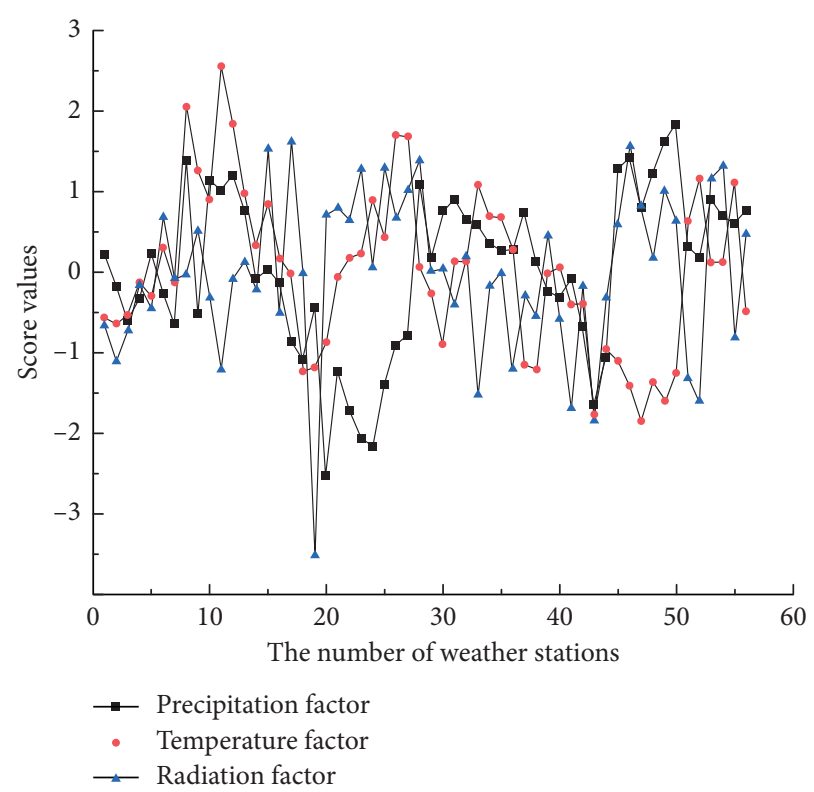

Figure 9: The score of the classification sample.

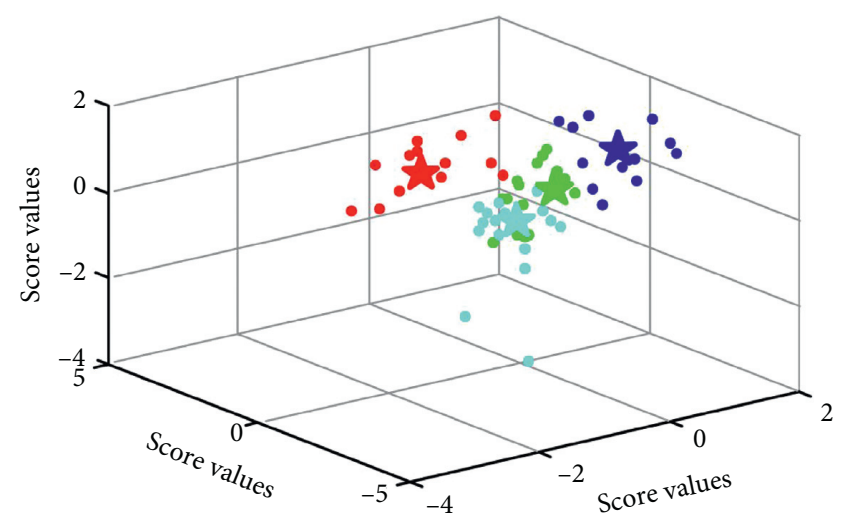

Figure 10: The clustering results.

resistance to low-temperature cracking should be used. It is also necessary to ensure stability of the asphalt pavement regarding exposure to high temperatures and water.

Zone II: this inland zone is characterized by high temperatures, little rainfall, and high radiation levels. This zone includes Yuzhong, Fuxin, Yixian, Yangshan, and Kazou in the northwest. The extreme maximum temperature reached $41.3^{\circ} \mathrm{C}$ and the key in this area is to focus on ensuring the high-temperature stability of the asphalt pavement. Therefore, asphalt mixture grading should be strictly controlled. A skeleton compact 


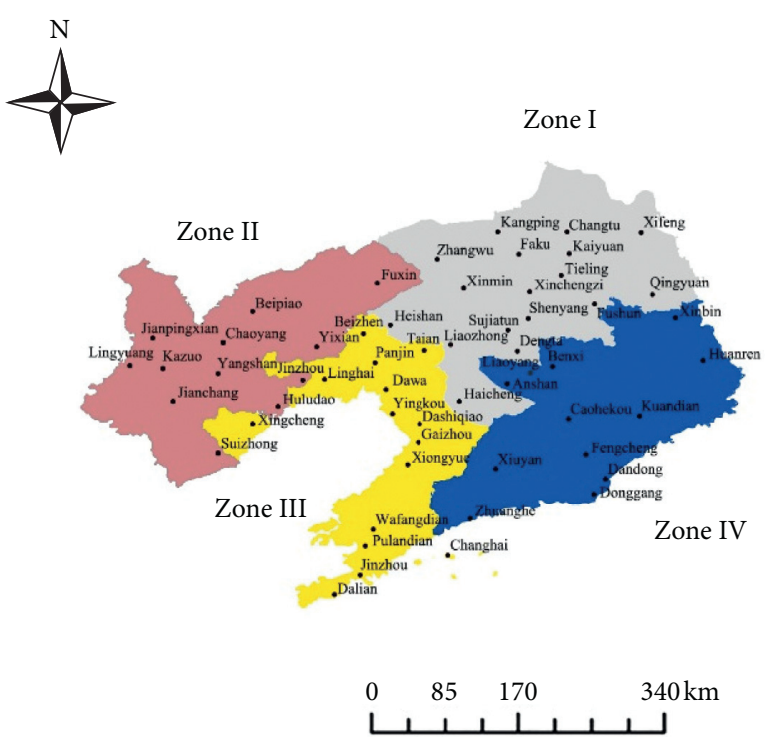

Figure 11: The specific regional types.

structure should be adopted. Asphalt modified or high modulus additives should be used to improve the rut resistance of the road. Low-temperature crack resistance and high-temperature rut resistance must also be taken into account when designing asphalt mixtures in this zone.

Zone III: this coastal zone is characterized by high temperatures and abundant rainfall. It includes Dalian, Yingkou, Panjin, and Gaizhou in the southwest, and the extreme maximum temperature reached $39.3^{\circ} \mathrm{C}$. The extreme maximum rainfall was $1132.5 \mathrm{~mm}$. Asphalt pavements in this zone should be guaranteed to have sufficient stability under high temperature and abundant rainfall conditions. At the same time, the pavement must have good antislip performance in view of the large amount of rainfall. Therefore, it is advisable to use stone mastic asphalts (SMA) and modified asphalts as much as possible.

Zone IV: this is a rainy and mountainous zone and includes Zhuanghe, Yuyan, Caohekou, Benxi, and Xinbin in the east. The area is subjected to considerable rainfall, with a maximum precipitation of $1765.5 \mathrm{~mm}$. Asphalt mixtures in this zone should be SMA, if necessary. The base material should have good erosion and corrosion resistance, and a dense framework structure should be adopted.

\section{Analysis and Prediction of Reliability}

5.1. Probabilistic Neural Network Classification Prediction. A PNN was established in this study through the use of the "newpnn" function in MATLAB. The input layer included the precipitation factor, temperature factor, and radiation factor. The output layer provided the four types of climate zones. After selecting data sets 1 to 36 as a training sample, the expected category was converted to a vector. Similarly, data sets 37 to 56 were used as test samples. The classification effect and error of the training data after training of the PNN are shown in Figure 12. The training samples were input into the established PNN network. The results showed that there was no error in the process of judging the sample data. Therefore, the PNN can perform additional sample classification predictions. The classification of the predicted data after the test is shown in Figure 13. Only two sets of data were handled incorrectly when 20 sets of samples were predicted. Therefore, the accuracy rate of the classification prediction was $90 \%$.

5.2. Support Vector Machine Classification Prediction. In this paper, an SVM climate regionalization model was established using the LIBSVM toolbox in the MATLAB software. Thirty-six sets of data were used as training sets and twenty sets of data were used as test sets, similarly to the PNN classification. In order to find the best parameter pair, the SVM parameters were selected by the grid search method. The generalization ability of each set of parameter pairs $(c, g)$ on the grid was evaluated. A cross-validation method called coefficient of variation was used to assess generalization capabilities. A three-dimensional view of the predicted accuracy was obtained through the LIBSVM toolbox and is shown in Figure 14.

The prediction model has the highest classification accuracy when the model parameters were $c=1.4$ and $g=4.0$, in which case the accuracy reached $94.4 \%$. Therefore, the optimal parameters of the model were determined by the cross-validation parameter search. Then, the SVM classification model was established. The classification prediction is shown in Figure 15. The similarity between the prediction results of the SVM and K-means clustering analysis of the climate regionalization was $95 \%$ which indicates that the $\mathrm{K}$-means clustering analysis results exhibited a reasonable degree of accuracy and reliability.

5.3. Verification of Physical Engineering. To further verify the reliability of the proposed regionalization method, this study compared the degradation of the pavement in the research regions with the results of the climate regionalization. Transverse cracks and longitudinal cracks were common in all studied roads. However, the situation in Zone I was the most serious, with cracking frequencies that reached $13.2 \%$ and $20.7 \%$ for the transverse and longitudinal cracks, respectively. Those same two conditions occurred with similar frequency in the other zones and were not representative; therefore, transverse and longitudinal cracks were not considered in other zones. The percentage of the damaged area on each road is shown in Figure 16.

A regionalization plan was generated for each road according to the method proposed in this study:

Zone I includes nine routes: Shida, Shenhuan, Zhangye, Liaokai, Chengguan, Qiansan, Muhua, Shenping, and Tiechang. The pavement damage consists mainly of alligator cracks, transverse cracks, longitudinal cracks, settlement and repairs, and rutting. The transverse cracks are typically a result of temperature shrinkage 


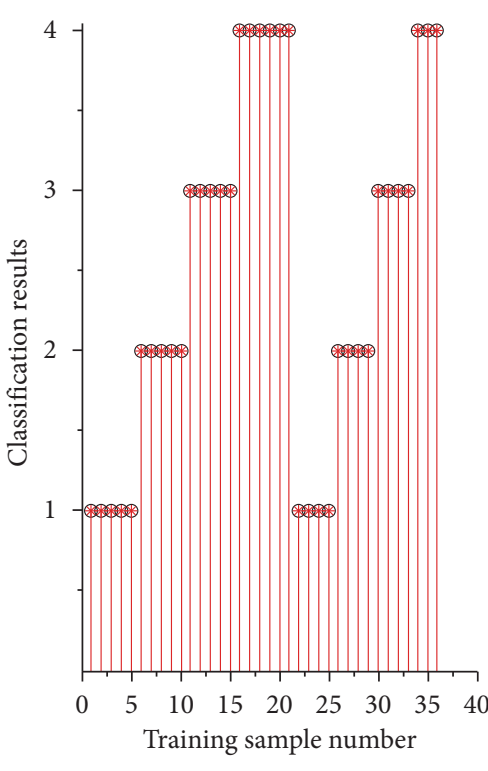

(a)

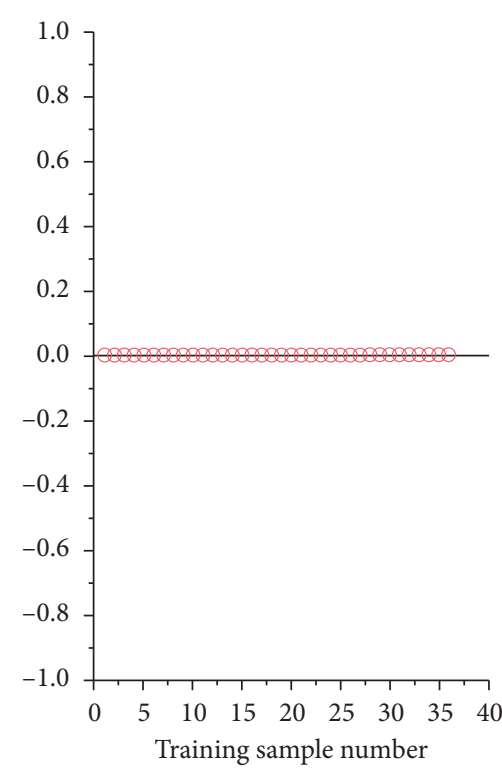

(b)

FIgURE 12: The effect and error of training data network classification. (a) The effect PNN network training and (b) The error map PNN network training.

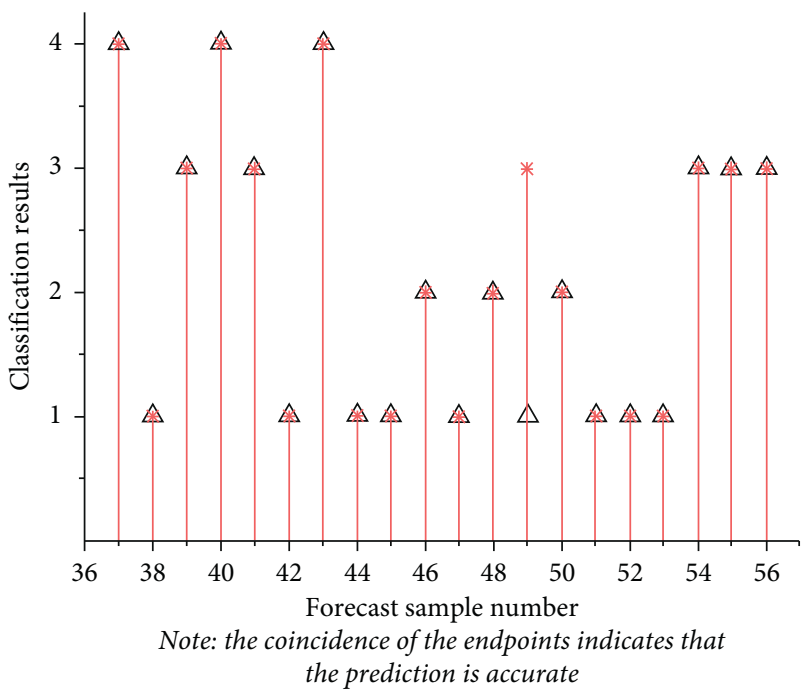

FIgURE 13: The classification effect of the predicted data. Note: the coincidence of the endpoints indicates that the prediction is accurate.

cracks. These types of cracks occur when water 3D view of parameter selection infiltrates along the cracks during a precipitation event, where it readily causes the loss of cementitious materials. In addition, water in the aggregate can cause peeling under the influence of vehicle loads and freeze-thaw cycles. Longitudinal cracks penetrate the base layer, which is weakly connected to the surface layer. These cracks are mainly the result of uneven settlement or frost heaving of the roadbed. Alligator cracks and rutting are the result of aging of the asphalt surface layer and fatigue of the inorganic binder layer. Settlement is mainly caused by insufficient

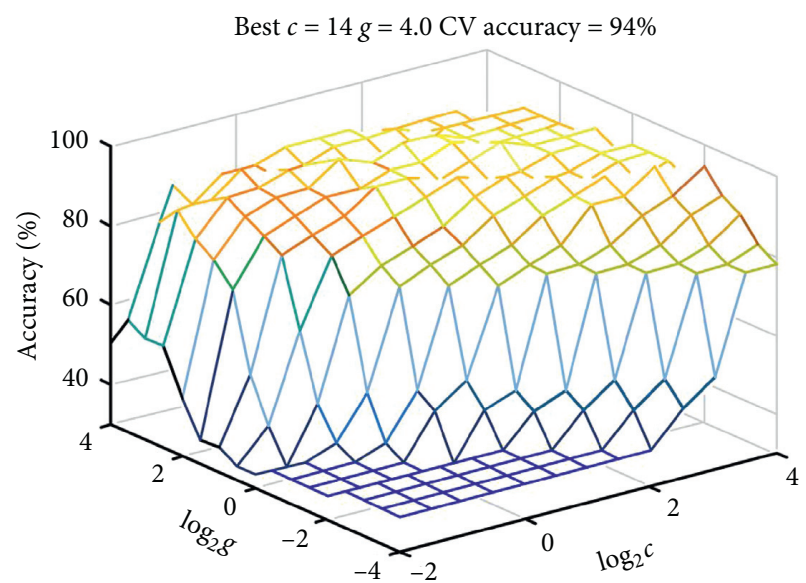

Figure 14: 3D view of parameter selection.

strength of the soil base when the base layer is eroded by water. Overall, the pavement is affected by high temperatures, low temperatures, and precipitation in Zone I.

Zone II includes five routes: Jinchi, Jingshen, Xiaoye, Anyang, and Binhai Road. The pavement degradation consists mainly of alligator cracks, rutting, shoving, and bleeding. The causes of cracks, rutting, and shoving in this zone are similar to those in Zone I and mainly arise as a result of insufficient overall road strength and the combined effect of vehicle loads and high temperatures. Overall, the pavement is most affected by high temperatures in Zone II.

Zone III includes a total of four routes: Haipi, Kuer, Zhuanglin, and Heida (Dalian). The pavement problems are mainly rutting and bleeding in this zone. The rut deformation occurs primarily in the asphalt mixture 


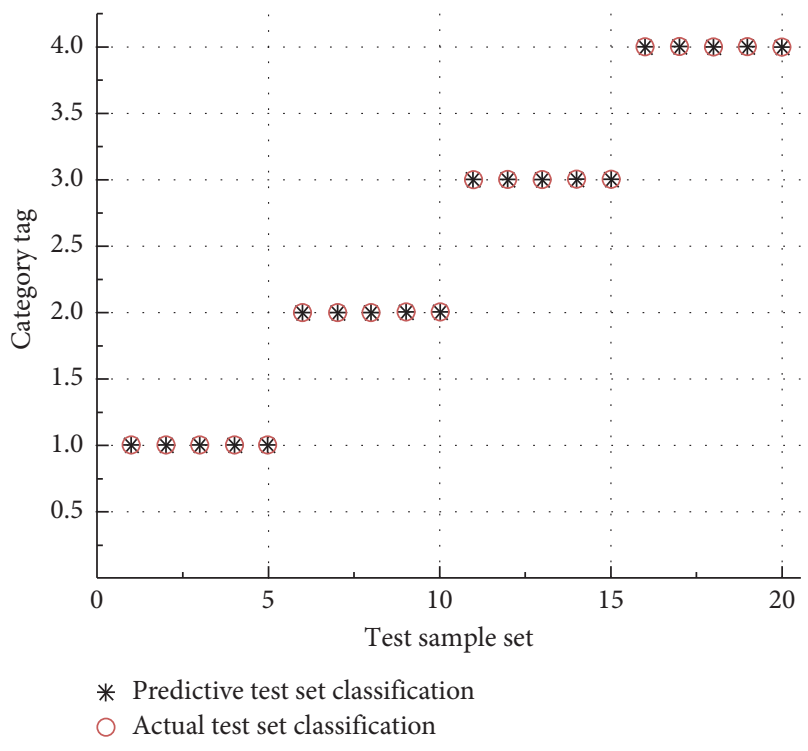

Figure 15: The classification prediction result.

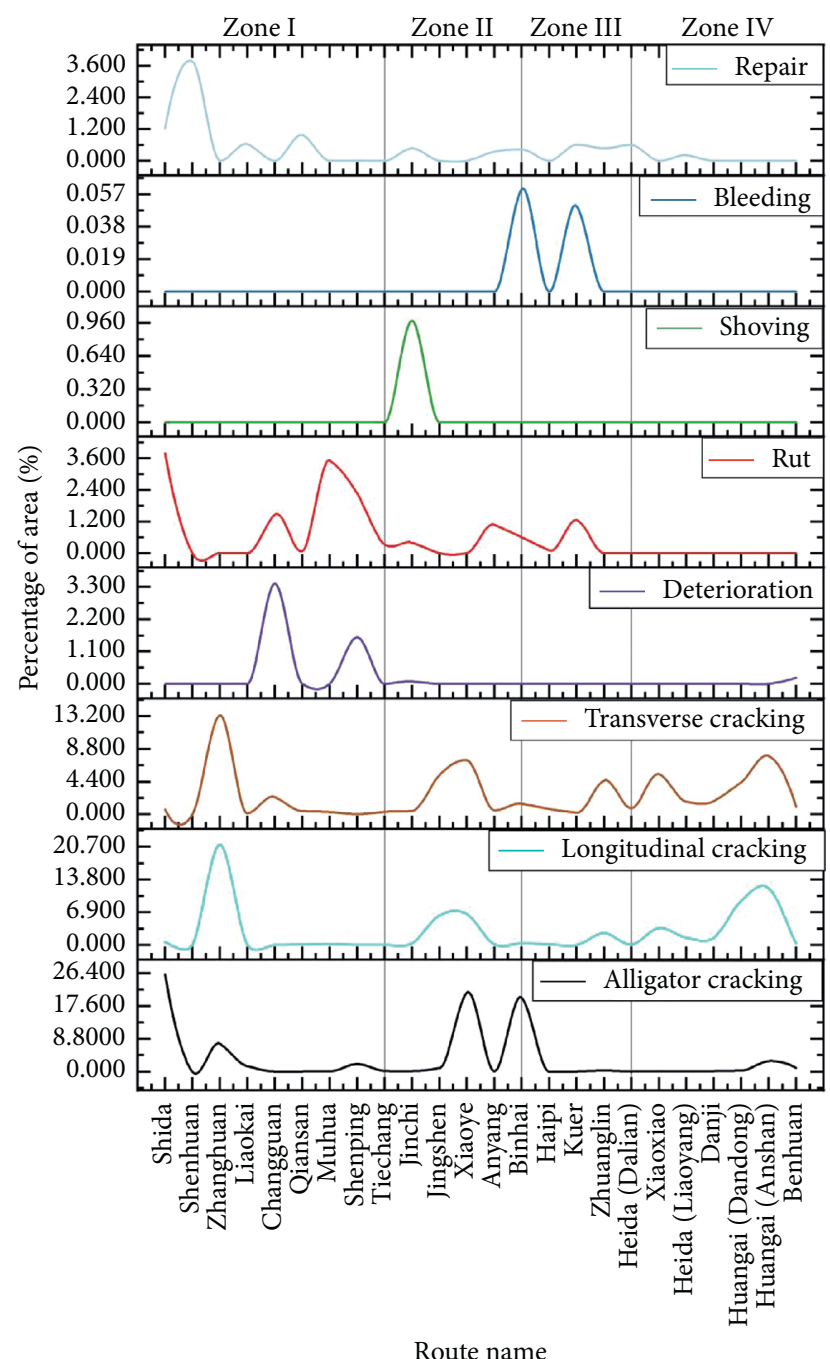

FIgURE 16: The percentage of degradation area on each road. layer. Judging from its deformation mode, the asphalt mixture undergoes lateral displacement and produces ruts under the repeated influence of high-temperature conditions and vehicle loads. Overall, the pavement is most primarily affected by high temperatures in Zone III.

Zone IV includes a total of six routes: Xiaoxiao, Heida (Liaoyang), Danji, Huanghai (Dandong), Huanghai (Anshan), and Benhuan. The pavement problems are mainly the result of alligator cracks, rutting, and bleeding. The road surfaces in Zone IV do not typically exhibit water-induced damage such as deterioration or pit slot. However, the cracks provide an opportunity for water damage. The cracks develop from top to bottom until they finally penetrate the surface layer. This results in a poor connection between the top layer and base layer. The core sample taken of the surface layer was significantly fragmented and had a low cement content and low strength. The process whereby these cracks develop is accelerated when water infiltrates the crack during a precipitation event and then remains in the base. In these circumstances, the bottom of the surface layer and the top of the base layer at the crack site are saturated for long periods of time. Vehicle loads generate hydrodynamic pressure, and temperature changes produce freeze-thaw cycles. The fine aggregate and cementitious materials peel off, and the adhesion between the surface layer and base layer is diminished. As the water has not penetrated the full depth, the base layer maintains good strength and a high cement content. Overall, precipitation is the main cause of road degradation in Zone IV.

In summary, the causes of pavement degradation in each road are consistent with the results of regionalization. Therefore, the method proposed in this study exhibits considerable reliability.

\section{Conclusions}

Based on the study of the climate regionalization of asphalt pavement, the following conclusions can be obtained:

(1) The four climate factors of high temperature, low temperature, precipitation, and solar radiation are analyzed in detail. These factors are the main causes of pavement damage. Nine major climate variables related to the four climate factors were proposed and a PCA was used to extract the three principal component factors of precipitation, temperature, and radiation from the main climate variables.

(2) The asphalt pavement in Liaoning Province was divided into four climate zones based on the $\mathrm{K}$-means clustering analysis method. Zone $\mathrm{I}$ is consistently affected by high temperatures, low temperatures, and precipitation; Zone II is an inland zone with high temperatures, little rainfall, and radiation; Zone III is a coastal zone with high temperatures; Zone IV is a rainy, mountainous zone. 
(3) The accuracy of the climate regionalization results was evaluated by the developed PNN and SVM prediction models. The results showed that the accuracy of the regionalization obtained from the K-means clustering algorithm was greater than $90 \%$. Thus, this method has clear accuracy and reliability.

(4) The method for the climate regionalization of asphalt pavements only analyzed the meteorological data of Liaoning Province in this paper. However, this method can serve as a reference and guidance for the design and construction of highway projects with similar climatic concerns around the world.

\section{Data Availability}

The data in this study can be obtained from the corresponding author upon request.

\section{Conflicts of Interest}

The authors declare that there are no conflicts of interest regarding the publication of this paper.

\section{Acknowledgments}

Thanks are due to Hindawi Editing Services in Editage online system. Thanks are due to the platform support provided by Shenyang Jianzhu University and the teachers' guidance for this research. This study was supported by Liaoning Distinguished Professor Program (Grant No. tpjs2017003) and the Key Program of Basic Scientific Research of Higher Education of Liaoning Province (Grant No. LJZ2017001).

\section{References}

[1] M. Sol-Sánchez, F. Moreno-Navarro, G. García-Travé, and M. C. Rubio-Gámez, "Laboratory study of the long-term climatic deterioration of asphalt mixtures," Construction and Building Materials, vol. 88, pp. 32-40, 2015.

[2] National Academies of Sciences, Engineering, and Medicine. Calibration and Validation of the Enhanced Integrated Climatic Model for Pavement Design, The National Academies Press, Washington, DC, USA, 2008.

[3] J. Harvey, A. Chong, and J. Roesler, Climate Regions for Mechanistic-Empirical Pavement Design in California and Expected Effects on Performance. CAL/APT Program, Pavement Research Center, Institute of Transportation Studies, University of California, Berkeley, CA, USA, 2000.

[4] Research Institute of Highway Ministry of Transport, Technical Specifications for Construction of Highway Asphalt Pavement: JTG F40-2004, China Communications Press, Beijing, China, 2004.

[5] M. Pszczoła, D. Ryś, and P. Jaskuła, "Analysis of climatic zones in Poland with regard to asphalt performance grading," Roads and Bridges-Drogi I Mosty, vol. 16, no. 4, pp. 245-264, 2017.

[6] P. Radziszewski, M. Sarnowski, J. Król et al., "Low-temperature requirements for bitumen in central east European road construction," The Baltic Journal of Road and Bridge Engineering, vol. 14, no. 2, pp. 249-270, 2019.
[7] I. M. Asi, "Performance evaluation of SUPERPAVE and Marshall asphalt mix designs to suite Jordan climatic and traffic conditions," Construction and Building Materials, vol. 21, no. 8, pp. 1732-1740, 2007.

[8] F. Viola and C. Celauro, "Effect of climate change on asphalt binder selection for road construction in Italy," Transportation Research Part D: Transport and Environment, vol. 37, pp. 40-47, 2015.

[9] P. Jitsangiam, P. Chindaprasirt, and H. Nikraz, "An evaluation of the suitability of SUPERPAVE and Marshall asphalt mix designs as they relate to Thailand's climatic conditions," Construction and Building Materials, vol. 40, pp. 961-970, 2013.

[10] S. Aflaki and N. Tabatabaee, "Proposals for modification of Iranian bitumen to meet the climatic requirements of Iran," Construction and Building Materials, vol. 23, no. 6, pp. 2141-2150, 2009.

[11] N. Bandara, S. Henson, and K. Klieber, "Creating a climate zone map for mechanistic empirical pavement designs," in Proceedings of the T\&DI Congress 2014, Orlando, FL, USA, June 2014.

[12] Y. Yang, Bo Hou, W. Hongfeng et al., “Application of spatial interpolation in asphalt pavement climate zoning: a case of temperature parameter," Highway Engineering, vol. 42, no. 5, pp. 22-27, 2017.

[13] F. Yunus, A. Shafie, J. Jaafar et al., "Homogeneous climate divisions for peninsular Malaysia," Geodinamica Acta, vol. 24, no. 2, pp. 89-94, 2011.

[14] J. M. Paruelo, W. K. Lauenroth, H. E. Epstein, I. C. Burke, M. R. Aguiar, and O. E. Sala, "Regional climatic similarities in the temperate zones of North and South America," Journal of Biogeography, vol. 22, no. 4-5, pp. 915-925, 1995.

[15] Y. Yang, S. Dong, B. Hou et al., "Climate zoning for asphalt pavement based on cluster analysis method," Journal of Chongqing Jiaotong University (Natural Science), vol. 37, no. 1, pp. 40-45, 2018.

[16] J. Rhee, J. Im, G. J. Carbone, and J. R. Jensen, "Delineation of climate regions using in-situ and remotely-sensed data for the Carolinas," Remote Sensing of Environment, vol. 112, no. 6, pp. 3099-3111, 2008.

[17] I. T. Jolliffe, "Pincipal component analysis," Journal of Marketing Research, vol. 25, no. 4, pp. 49-63, 2002.

[18] H. Liu and J. Wang, "Integrating independent component analysis and principal component analysis with neural network to predict Chinese stock market," Mathematical Problems in Engineering, vol. 2011, Article ID 382659, 15 pages, 2011.

[19] X. Xu and C. Wen, "Fault diagnosis method based on information entropy and relative principal component analysis," Journal of Control Science and Engineering, vol. 2017, Article ID 2697297, 8 pages, 2017.

[20] A. K. Jain, "Data clustering: 50 years beyond K-means," Pattern Recognition Letters, vol. 31, no. 8, pp. 651-666, 2010.

[21] S. G. Wu, F. S. Bao, E. Y. Xu, Y.-X. Wang, Y.-F. Chang, and Q.-L. Xiang, "A leaf recognition algorithm for plant classification using probabilistic neural network," in Proceedings of the 2007 IEEE International Symposium on Signal Processing and Information Technology, pp. 11-16, Giza, Egypt, December 2007.

[22] D. F. Specht, "Probabilistic neural networks," Neural Networks, vol. 3, no. 1, pp. 109-118, 1990.

[23] A. Chaudhuri, K. De, and D. Chatterjee, "A comparative study of kernels for the multi-class support vector machine," in 
Proceedings of the 2008 Fourth International Conference on Natural Computation, pp. 3-7, Jinan, China, October 2008.

[24] I. Leonovich and I. Melnikova, "Influence of temperature on the formation of damages in asphalt concrete pavements under climatic conditions of the republic of Belarus," The Baltic Journal of Road and Bridge Engineering, vol. 7, no. 1, pp. 42-47, 2012.

[25] S. Hussan, M. A. Kamal, I. Hafeez, D. Farooq, N. Ahmad, and S. Khanzada, "Statistical evaluation of factors affecting the laboratory rutting susceptibility of asphalt mixtures," International Journal of Pavement Engineering, vol. 20, no. 4, pp. 402-416, 2019.

[26] H. Kim, S.-J. Lee, S. N. Amirkhanian, and K.-D. Jeong, "Quantification of oxidative aging of polymer-modified asphalt mixes made with warm mix technologies," Journal of Materials in Civil Engineering, vol. 25, no. 1, pp. 1-8, 2013.

[27] D. Rys, J. Judycki, M. Pszczola, M. Jaczewski, and L. Mejlun, "Comparison of low-temperature cracks intensity on pavements with high modulus asphalt concrete and conventional asphalt concrete bases," Construction and Building Materials, vol. 147, pp. 478-487, 2017.

[28] Y. Yang, Y. Yang, and B. Qian, "Performance and microstructure of cold recycled mixes using asphalt emulsion with different contents of cement," Materials, vol. 12, no. 16, p. $2548,2019$.

[29] K. L. Vasconcelos, A. Bhasin, and D. N. Little, "History dependence of water diffusion in asphalt binders," International Journal of Pavement Engineering, vol. 12, no. 5, pp. 497-506, 2011.

[30] J. Saha, S. Nassiri, A. Bayat, and H. Soleymani, "Evaluation of the effects of Canadian climate conditions on the MEPDG predictions for flexible pavement performance," International Journal of Pavement Engineering, vol. 15, no. 5, pp. 392-401, 2014.

[31] M. R. Mohd Hasan, J. E. Hiller, and Z. You, "Effects of mean annual temperature and mean annual precipitation on the performance of flexible pavement using ME design," International Journal of Pavement Engineering, vol. 17, no. 7, pp. $647-658,2016$.

[32] M. Heidari-Rarani, M. R. M. Aliha, M. M. Shokrieh, and M. R. Ayatollahi, "Mechanical durability of an optimized polymer concrete under various thermal cyclic loadings-an experimental study," Construction and Building Materials, vol. 64, pp. 308-315, 2014.

[33] E. Özgan and S. Serin, "Investigation of certain engineering characteristics of asphalt concrete exposed to freeze-thaw cycles," Cold Regions Science and Technology, vol. 85, pp. 131-136, 2013.

[34] J. Basheer Sheeba and A. Krishnan Rohini, "Structural and thermal analysis of asphalt solar collector using finite element method," Journal of Energy, vol. 2014, Article ID 602087, 9 pages, 2014

[35] Maria de Fátima Amazonas de Sá Araujo, V. F. C. Lins, V. M. D. Pasa, and L. F. Mathias Leite, "Weathering aging of modified asphalt binders," Fuel Processing Technology, vol. 115, pp. 19-25, 2013.

[36] W. Zeng, S. Wu, J. Wen, and Z. Chen, "The temperature effects in aging index of asphalt during UV aging process," Construction and Building Materials, vol. 93, pp. 1125-1131, 2015.

[37] S. Xu, J. Yu, Y. Sun, and S. Wu, "Synthesis and characterization of organic intercalated layered double hydroxides and their application in bitumen modification," Materials Chemistry and Physics, vol. 152, pp. 54-61, 2015.
[38] Y. Tan, J. Wang, Z. Xue, Z. Feng, and H. Xu, "Laboratory study on ultraviolet aging behavior of asphalt binder and mixture," in Proceedings of the Seventh International Conference of Chinese Transportation Professionals Congress (ICCTP), Shanghai, China, May 2007. 